\title{
Comparative Analysis of Exact Solutions for the Phi-four Equation
}

\author{
Phi-four Denkleminin Tam Çözümlerinin Karşılaştırmalı Analizi
}

\begin{abstract}
Şamil AKÇAĞIL*
Pazaryeri Vocational School, Bilecik Şeyh Edebali University, Bilecik, Turkey

• Geliş tarihi / Received: 07.01.2019 • Düzeltilerek geliş tarihi / Received in revised form: 08.03.2019 • Kabul tarihi / Accepted: 20.03 .2019

Abstract

The Phi-4 equation plays an important role in mathematical physics and it is particular form of the Klein-Gordon equation that models the phenomenon in particle physics. This significant equation has been studied by many researchers and many solutions to this equation have been obtained by using different methods. In this study, the solutions obtained by three important methods have been focused on: The modified simple equation method, the ansatz method and He's variational method. Reconsidering the phi-4 equation, the same solutions and new trigonometric, hyperbolic and elliptic function solutions have been obtained by using the sn-ns method. The similarities and differences of the obtained solutions have been compared with each other. In addition to its easy applicability, the sn-ns method was shown to be highly effective and reliable method.
\end{abstract}

Keywords: Ansatz method, He's variational method, Modified simple equation method, Phi-four equation, Sn-ns method

\section{$\ddot{O} z$}

Matematiksel fizikte önemli bir rol oynayan Phi-4 denklemi, bu olguyu parçacık fiziğinde modelleyen Klein-Gordon denkleminin özel bir halidir. Bu önemli denklem birçok araştırmacı tarafindan çalışlmış ve bu denklemin birçok çözümü farkl yöntemler kullanılarak elde edilmiştir. Bu çalışmada, üç önemli yöntemle elde edilen çözümlere odaklanıldl: Modifiye edilmiş basit denklem yöntemi, ansatz yöntemi ve He'nin varyasyonel yöntemi. Phi-dört denklemi yeniden göz önüne alınarak, daha önce elde edilmiş çözümlerin yanında yeni trigonometrik, hiperbolik ve eliptik fonksiyon çözümleri sn-ns yöntemi kullanılarak elde edildi. Elde edilen çözümlerin benzerlikleri ve farklılıkları birbirleriyle karşılaştırlldı. Kolay uygulanabilirliğinin yanında, sn-ns metodun oldukça etkin ve güvenilir bir yöntem olduğu gösterildi.

Anahtar kelimeler: Ansatz metodu, He'nin varyasyonel metodu, Modifiye edilmiş basit denklem metodu, Phi-four denklemi, Sn-ns metodu

*Şamil AKÇAĞIL; samilakcagil@hotmail.com; Tel: (0228) 214 16 54; orcid.org/0000-0002-8510-9683 


\section{Introduction}

One of the well-known Phi-4 equations is given by

$u_{t t}-\alpha u_{x x}-\lambda u+\beta u^{3}=0$,

where $\alpha, \beta$ and $\lambda$ are real constants. Its name being due to the expression

$K=\frac{1}{2}\left(\phi_{t}^{2}+\phi_{x}^{2}\right)-\frac{1}{2} \phi^{2}+\frac{1}{4} \phi^{4}$

of the corresponding Hamiltonian density. This equation has been the subject of intensive investigation in the context of classical and quantised field theory and it has been mainly investigated as the simplest non trivial relativistic invariant field theoretical model (Calogero and Degasperis, 1982). Several forms of the phi-four equation have been studied extensively by many researchers and obtained different solutions. In this study, we have focused on the solutions obtained by three important methods: The modified simple equation method, the ansatz method and He's variational method.

Akter and Akbar have considered the Phi-4 equation in the form

$u_{t t}-u_{x x}+a^{2} u+b u^{3}=0$,

where $a$ and $b$ are real valued constants (Akter and Akbar, 2015). By applying the modified simple equation method and using the wave variable $=x+c t$, they have found the following solutions:

$u_{1}(x, t)= \pm \sqrt{-\frac{a^{2}}{b}} \tanh \left(\frac{1}{2} \sqrt{\frac{2}{c^{2}-1}} a(x+c t)\right)$

$u_{2}(x, t)= \pm \sqrt{-\frac{a^{2}}{b}} \operatorname{coth}\left(\frac{1}{2} \sqrt{\frac{2}{c^{2}-1}} a(x+c t)\right)$.

In Cao at al. (2014), the authors have obtained the topological 1-soliton solution or kink solution of the equation

$u_{t t}-k^{2} u_{x x}-a u-b u^{3}=0$,

by the ansatz method where parameters $k, a$ and $b$ are all real-valued constants. In order to obtain soliton solution of (6), they have taken the ansatz

$u(x, t)=A \tanh ^{p} \tau$

where
$\tau=B(x+c t)$

Here in (7) and (8), the parameters $A$ and $B$ are known as free parameters of the soliton or the kink and $\mathrm{c}$ is the velocity of the soliton. Thus, they have given the 1-soliton solution to the equation (6) as follows:

$u(x, t)=\sqrt{-\frac{a}{b}} \tanh \left(\sqrt{-\frac{a}{2\left(c^{2}-k^{2}\right)}}(x+c t)\right)$.

Najafi, by means of the He's variational method, has obtained solitary solutions of the following phi-four equation:

$u_{t t}-\alpha u_{x x}-u+u^{3}=0$,

where $\alpha$ is an arbitrary constant (Najafi, 2012). The author has used the ansatz

$u(x, t)=A \operatorname{sech}(x+c t)$

in variational formulation and consequently, obtained the following solitary solutions:

$u_{1}(x, t)=\frac{\sqrt{6+2\left(c^{2}-\alpha\right)}}{2} \operatorname{sech}(x+c t)$,

$u_{2}(x, t)=-\frac{\sqrt{6+2\left(c^{2}-\alpha\right)}}{2} \operatorname{sech}(x+c t)$,

where $c$ and $\alpha$ are arbitrary constants.

The projective Riccati equations can be used to obtain powerful methods that allow us to solve many nonlinear ordinary and partial differential equations in closed form. The sn-ns method is one of the methods mentioned and it provides elliptic function solutions as well as trigonometric, complex and hyperbolic solutions.

Motivated by the above valuable works, we will study a generalized form of the phi-four equation given by

$u_{t t}-\alpha u_{x x}-\lambda u+\beta u^{3}=0$,

where $\alpha, \beta$ and $\lambda$ are real constants. In this study, we will apply the sn-ns method for solving the phi-four equation and obtain new exact solutions. The similarities and differences of the obtained solutions will be compared with each other.

\section{A Brief Introduction to Jacobi Elliptic Functions}

The Jacobi elliptic functions are standard forms of elliptic functions and they can be defined with 
respect to certain integrals. The sn-ns method provides an exact solution to differential equations in terms of the three basic Jacobi elliptic functions $\operatorname{cn}(u, m), \operatorname{dn}(u, m)$ and $\operatorname{sn}(u, m)$. Thus if

$u=\int_{0}^{\varphi} \frac{d \theta}{\left(1-m^{2} \sin ^{2} \theta\right)^{\frac{1}{2}}}$

the angle $\varphi$ is called the amplitude and its shown as

$\mathrm{sn}^{2}(u, m)+\mathrm{cn}^{2}(u, m)=1$,

$m^{2} \operatorname{sn}^{2}(u, m)+\operatorname{dn}^{2}(u, m)=1$,

$m^{2} \mathrm{cn}^{2}(u, m)+\left(1-m^{2}\right)=\operatorname{dn}^{2}(u, m)$,

$\mathrm{cn}^{2}(u, m)+\left(1-m^{2}\right) \operatorname{sn}^{2}(u, m)=\operatorname{dn}^{2}(u, m)$.

The basic jacobian elliptic functions also hold the following identities in the special cases:

$\operatorname{sn}(u, 0)=\sin u, \quad \operatorname{cn}(u, 0)=\cos u, \quad \operatorname{dn}(u, 0)=1, \quad \operatorname{sn}(u, 1)=\tanh u$

$\operatorname{cn}(u, 1)=\operatorname{sech} u, \quad \operatorname{dn}(u, 1)=\operatorname{sech} u, \quad \operatorname{sn}(0, m)=0, \quad \operatorname{cn}(0, m)=1$

$\operatorname{dn}(0, m)=1, \quad \operatorname{sn}(u, 1)=\tanh u, \quad \operatorname{cn}(u, 1)=\operatorname{sech} u, \quad \operatorname{dn}(u, 1)=\operatorname{sech} u$

These functions are derivable and the derivatives of the three basic Jacobi functions with respect to variable $u$ can be expressed through other basic Jacobi functions:

$\frac{\partial \operatorname{sn}(u, m)}{\partial u}=\operatorname{cn}(u, m) \operatorname{dn}(u, m)$,

$\frac{\partial \operatorname{cn}(u, m)}{\partial u}=-\operatorname{sn}(u, m) \operatorname{dn}(u, m)$,

$\frac{\partial d n(u, m)}{\partial u}=-m^{2} \operatorname{sn}(u, m) \operatorname{cn}(u, m)$.

The combinations of the letters $s, c, d, n$ give a total of 12 functions: cd, cn, cs, dc, dn, ds, nc, nd, ns, sc, sd, and sn. Generally if $p, q, r$ are any three of the letters $s, c, d$ and $n$, these 12 functions can be derived as follows:

$\operatorname{pqu}=\frac{\operatorname{pr} u}{\mathrm{qr} u}$

Thus, relation of the Jacobian functions to the $\operatorname{sn} u, \operatorname{cn} u$ and $\operatorname{dn} u$ can be written as follows:

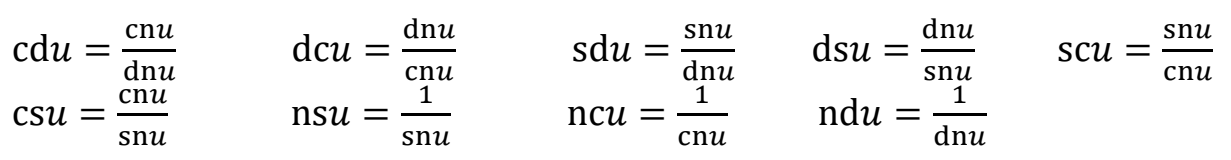

For more details on the Jacobian elliptic functions we refer the interested readers to Abramowitz and Stegun (1972).

\section{The sn-ns method}

The sn-ns method has been introduced by Salas and Castillo (Salas and Castillo, 2011). Salas has considered the Ito equation and obtained some solutions of the equation by using the sn-ns method (Salas, 2011). We can summarize the method as follows:

Step 1. First, consider a general form of the nonlinear equation

$P\left(u, u_{t}, u_{x}, u_{x x}, u_{x t}, u_{t t}, \ldots\right)=0$. 
Step 2. To find the traveling wave solution of equation (25), we use wave transformation

$u(x, t)=U(\xi)$ and $\xi=x+c t$,

where $c$ is a constant.

Step 3. Using (26) changes PDE (25) to an ODE

$Q\left(U, U^{\prime}, U^{\prime \prime}, \ldots\right)=0$.

Step 4. If necessary we integrate (27) as many times as possible. Adhering to the boundary conditions for $\xi \rightarrow \pm \infty$,

$U(\xi) \rightarrow 0, \frac{d^{\mathrm{n}} U(\xi)}{d \xi^{\mathrm{n}}} \rightarrow 0 \quad(n=1,2,3, \ldots)$,

the integration constants should all be set zero.

Step 5. To obtain the solutions of (27) we try one of the following ansatz:

$U(\xi)=\sum_{i=0}^{M} a_{i} \mathrm{sn}^{i}(k \xi, m)+\sum_{i=1}^{M} b_{i} \mathrm{~ns}^{i}(k \xi, m)$

$U(\xi)=\sum_{i=0}^{M} a_{i} \mathrm{cn}^{i}(k \xi, m)+\sum_{i=1}^{M} b_{i} \mathrm{nc}^{i}(k \xi, m)$

$U(\xi)=\sum_{i=0}^{M} a_{i} \operatorname{dn}^{i}(k \xi, m)+\sum_{i=1}^{M} b_{i} \operatorname{nd}^{i}(k \xi, m)$

where $k, a_{i}, b_{i}$ are constants and $M$ is an integer in most cases. If $M$ is not an integer, this problem can be solved by using a transformation formula.

Step 6. Before we look for the solutions we must first determine the parameter $M$. To determine the parameter $M$, the linear terms of highest order in the resulting equation with the highest power nonlinear terms are balanced. When $M$ determined, using (29), (30) or (31) and (22) in (27), we get a polynomial of Jacobian elliptic functions. All the coefficients of powers of elliptic functions in the resulting equation must be zero. This yields a set of algebraic equations for $k, a_{i}$ ,$b_{i}$ and $c(i=0,1,2, \ldots, M)$. Solving the equation system we obtain an analytic solution in a closed form.

\section{The Exact Solutions of the Phi-four Equation by using the sn-ns method}

We now consider the generalized form of the phifour equation

$u_{t t}-\alpha u_{x x}-\lambda u+\beta u^{3}=0$,

where $\alpha, \beta$ and $\lambda$ are real constants. Using the following transformation

$u(x, t)=U(\xi), \xi=x+c t$

we can carry (32) into the following ODE $\left(c^{2}-\alpha\right) U^{\prime \prime}-\lambda U+\beta U^{3}=0$.

Balancing $U^{\prime \prime}$ with $U^{3}$, we find $M+2=3 M$ and $M=1$. In view of the sn-ns method we could assume the solution of (34) has the ansatz form

$U(\xi)=a_{0}+a_{1} \operatorname{sn}(k \xi, m)+b_{1} \mathrm{~ns}(k \xi, m)$.

Substituting (35) with the derivatives

$\frac{\partial^{2} \mathrm{sn}}{\partial \xi^{2}}=$

$2 m^{2} k^{2} \mathrm{sn}^{3}(k \xi, m)-\left(m^{2}+1\right) k^{2} \operatorname{sn}(k \xi, m)$,

$\frac{\partial^{2} \mathrm{~ns}}{\partial \xi^{2}}=2 \mathrm{~ns}^{3}(k \xi, m)-\left(m^{2}+1\right) \mathrm{ns}(k \xi, m)$,

into (34) and considering ns $u=1 / \operatorname{sn} u$, we obtain a polynomial equation with respect to the variable $\phi=\operatorname{sn}(k \xi, m)$. If we collect the coefficients of each power of $\phi$ and set each coefficient to zero then find a system of algebraic equation system for $a_{i}, b_{i}, k$ and $c$. Solving the resulting system of algebraic equations, we find the following exact solutions:

$u_{1,2}= \pm \sqrt{\frac{2 \lambda m^{2}}{\beta\left(m^{2}+1\right)}} \operatorname{sn}\left(\sqrt{\frac{-\lambda}{\left(m^{2}+1\right)\left(c^{2}-\alpha\right)}}(x+c t), m\right)$,

$u_{3,4}= \pm \sqrt{\frac{2 \lambda}{\beta\left(m^{2}+1\right)}} \mathrm{ns}\left(\sqrt{\frac{-\lambda}{\left(m^{2}+1\right)\left(c^{2}-\alpha\right)}}(x+c t), m\right)$,

$u_{5,6}=\sqrt{\frac{2 \lambda m^{2}}{\beta\left(m^{2}+6 m+1\right)}} \operatorname{sn}\left(\sqrt{\frac{-\lambda}{\left(m^{2}+6 m+1\right)\left(c^{2}-\alpha\right)}}(x+c t), m\right)+$

$\sqrt{\frac{2 \lambda}{\beta\left(m^{2}+6 m+1\right)}} \mathrm{ns}\left(\sqrt{\frac{-\lambda}{\left(m^{2}+6 m+1\right)\left(c^{2}-\alpha\right)}}(x+c t), m\right)$,

$u_{7,8}=\sqrt{\frac{2 \lambda m^{2}}{\beta\left(m^{2}-6 m+1\right)}} \operatorname{sn}\left(\sqrt{\frac{-\lambda}{\left(m^{2}-6 m+1\right)\left(c^{2}-\alpha\right)}}(x+c t), m\right)+$

$\sqrt{\frac{2 \lambda}{\beta\left(m^{2}-6 m+1\right)}} \mathrm{ns}\left(\sqrt{\frac{-\lambda}{\left(m^{2}-6 m+1\right)\left(c^{2}-\alpha\right)}}(x+c t), m\right)$,

where $c$ is left as a free parameter. We can use any other useful ansatz to obtain other solutions of (34). Now, we try the following ansatz:

$U(\xi)=a_{0}+a_{1} \operatorname{cn}(k \xi, m)+b_{1} \mathrm{nc}(k \xi, m)$.

Using the same procedure we obtain following solutions to equation (34):

$u_{9,10}= \pm \sqrt{\frac{2 \lambda m^{2}}{\beta\left(2 m^{2}-1\right)}} \operatorname{cn}\left(\sqrt{\frac{\lambda}{\left(2 m^{2}-1\right)\left(c^{2}-\alpha\right)}}(x+c t), m\right)$,

$u_{11,12}= \pm \sqrt{\frac{2\left(1-m^{2}\right) \lambda}{\beta\left(1-m^{2}\right)}} \mathrm{nc}\left(\sqrt{\frac{\lambda}{\left(2 m^{2}-1\right)\left(c^{2}-\alpha\right)}}(x+c t), m\right)$,

where $\mathrm{c}$ is left as a free parameter. 


\section{Comparison of the solutions}

In this section, we have compared the solutions obtained by the sn-ns method in this study with those obtained by modified simple equation method, the ansatz method and He's variational method.

We first consider the solutions (38) and (39) obtained by the sn-ns method in this work:

$u_{1,2}= \pm \sqrt{\frac{2 \lambda m^{2}}{\beta\left(m^{2}+1\right)}} \operatorname{sn}\left(\sqrt{\frac{-\lambda}{\left(m^{2}+1\right)\left(c^{2}-\alpha\right)}}(x+c t), m\right)$,

$u_{3,4}= \pm \sqrt{\frac{2 \lambda}{\beta\left(m^{2}+1\right)}} \mathrm{ns}\left(\sqrt{\frac{-\lambda}{\left(m^{2}+1\right)\left(c^{2}-\alpha\right)}}(x+c t), m\right)$.

Setting $\alpha=1, \lambda=-a^{2}$ and $\beta=b$, we get the following solutions respectively:

$\tilde{u}_{1,2}= \pm \sqrt{-\frac{2 a^{2} m^{2}}{b\left(m^{2}+1\right)}} \operatorname{sn}\left(\sqrt{\frac{a^{2}}{\left(m^{2}+1\right)\left(c^{2}-1\right)}}(x+c t), m\right)$

$\tilde{u}_{3,4}= \pm \sqrt{-\frac{2 a^{2} m^{2}}{b\left(m^{2}+1\right)}} \mathrm{ns}\left(\sqrt{\frac{a^{2}}{\left(m^{2}+1\right)\left(c^{2}-1\right)}}(x+c t), m\right)$.

As stated before in (21) and (24) when $m \rightarrow 1$ the following equalities hold:

$\operatorname{sn}(u, m)=\tanh u$

$\operatorname{ns}(u, m)=\operatorname{coth} u$

Thus, the solutions $u_{1,2}$ and $u_{3,4}$ degenerate into the solutions (4) and (5) obtained by the modifed simple equation method.

Also, setting $\alpha=k^{2}, \lambda=a, \beta=-b$ in (38) we get

$\tilde{u}_{5,6}= \pm \sqrt{-\frac{2 a m^{2}}{b\left(m^{2}+1\right)}} \operatorname{sn}\left(\sqrt{\frac{-a}{\left(m^{2}+1\right)\left(c^{2}-k^{2}\right)}}(x+c t), m\right)$.

Taking $m \rightarrow 1$, the last solution reduces to the solution (9) obtained by the ansatz method.

We next consider the solution (43) obtained by the sn-ns method in this work:

$u_{9,10}= \pm \sqrt{\frac{2 \lambda m^{2}}{\beta\left(2 m^{2}-1\right)}} \operatorname{cn}\left(\sqrt{\frac{\lambda}{\left(2 m^{2}-1\right)\left(c^{2}-\alpha\right)}}(x+c t), m\right)$,

Setting $\lambda=\beta=1$, we obtain following solutions: $\tilde{u}_{9,10}= \pm \sqrt{\frac{2 m^{2}}{2 m^{2}-1}} \operatorname{cn}\left(\sqrt{\frac{1}{\left(2 m^{2}-1\right)\left(c^{2}-\alpha\right)}}(x+c t), m\right)$.

From (21), in the limit case $m \rightarrow 1$, we can write $\operatorname{cn}(u, m)=\operatorname{sech} u$.
So, the solution (43) turns into the solution:

$u= \pm \sqrt{2} \operatorname{sech}\left(\frac{1}{\sqrt{c^{2}-\alpha}}\right)(x+c t)$.

It can be seen easily that (45) degenerate into the solutions (12) and (13) for $c^{2}=\alpha+1$.

\section{Conclusion}

We have given a brief introduction to Jacobi elliptic functions. Using basic Jacobi elliptic functions sn,cn and dn we have summarized the sn-ns method. The method has been successfully implemented to find travelling wave solutions for the Phi-4 equation. Although we have had the same solutions found by the modified simple equation method, the ansatz method and He's variational method, the sn-ns method have given trigonometric and elliptic function solutions in addition to hyperbolic solutions. Therefore, the sn-ns method is useful and trustworthy method to get more solutions to NLPDEs. Throughout the work, Maple and Mathematica have been used to overcome the tedious algebraic calculations.

\section{References}

Abramowitz, M. and Stegun, I. A., 1972. Handbook of Mathematical Functions: with Formulas, Graphs, and Mathematical Tables, 9th printing, New York, Dover, 1046p.

Akter, J. and Akbar, M. A., 2015. Exact solutions to the Benney-Luke equation and the Phi-4 equations by using modified simple equation method. Results in Physics, 5, 125-130.

Calogero, F. and Degasperis, A., 1982. Spectral Transform and Solitons: Tools to Solve and Investigate Nonlinear Evolution Equations. New York: North-Holland, 532p.

Cao, J., Song, M. and Biswas, A., 2014. Topological Solitons and Bifurcation Analysis of the PHIFour Equation. Bull. Malays. Math. Sci. Soc., 37, 1209-1219.

Najafi, M., 2012. Using He's Variational Method to Seek the Traveling Wave Solution of PHI-Four Equation. International Journal of Applied Mathematical Research, 1, 659-665.

Salas H. A., 2011. Exact Solutions for the Ito Equation by the sn-ns Method. Applied Mathematical Sciences, 5, 2283-2287.

Salas, H.A. and Castillo, J.E., 2011. New exact solutions to sinh-cosh-Gordon equation by using techniques based on projective Riccati equations. Computers and Mathematics with Applications, 61, 470-481. 